\title{
"Ensiná-los a Viver": a Política de Saúde Pública, da Tuberculose à AIDS*
}

ALAN SEARS

\section{Introdução}

Em todo o mundo, os Estados têm respondido à AIDS primordialmente através de políticas de saúde pública; estas têm ocupado o primeiro plano nos esforços para identificar as causas da epidemia e deter sua disseminação. No entanto, as respostas dessas políticas têm sido contraditórias, dividindo-se entre medidas práticas para combater a epidemia e a promoção de modos particulares de vida (como a heterossexualidade, a monogamia e a abstinência do uso de drogas). A natureza contraditória de tais respostas não é uma anomalia peculiar à sociologia da AIDS, mas encontra profundas raízes na teoria e na prática da saúde pública.

Já existe uma rica literatura voltada para a compreender essa contradição através da análise crítica das políticas de saúde, em uma perspectiva histórica e contemporânea. Boa parte desses estudos caracteriza-se por levantar questões teóricas mais amplas a respeito da base sociológica da teoria e da prática da saúde pública. Os trabalhos que examinaram as questões sociológicas tendem a fazê-lo nos termos do que se poderia chamar de uma "teoria da cultura", que recorre - embora com diferentes

* Tradução de Vera Pereira. O artigo foi publicado originalmente em Journal of Historical Sociology, v. $5, \mathrm{n}^{\mathrm{O}} 1$, março de 1992. 
ênfases - às obras de Foucault, ao "pluralismo radical" e aos métodos do pós-modernismo. ${ }^{1} \mathrm{O}$ conjunto dessas obras constitui uma rejeiçāo, implícita ou explícita, das teorias marxistas do Estado e das análises sobre a política social produzidas desde os anos 70 .

Este artigo defende a relevância da teoria marxista do Estado para a compreensão da política de saúde pública desde a tuberculose até a AIDS. A literatura a respeito da "teoria da cultura" nesse campo já forneceu convincentes insights ao que $\mathrm{Tesh}^{2}$ denomina de "argumentos ocultos" na teoria e na prática da saúde pública. Essa literatura tem, no entanto, ignorado as ricas possibilidades da investigação das políticas nessa área como uma prática estatal de regulação, modelada e limitada pelas preocupações maiores que governam a formação da política social. Neste artigo, procuro introduzir as percepções da "teoria da cultura" no contexto do materialismo histórico.

O "exemplo" empírico utilizado para defender esse argumento teórico tomará como referência o desenvolvimento da saúde pública no Canadá no século XX. Durante as duas primeiras décadas, houve uma intensa expansāo dos programas de saúde pública nesse país, centrados na teoria e na prática da "nova higiene". Os métodos desenvolvidos durante esse período continuaram a influenciar a estratégia de saúde pública do país até os dias de hoje. ${ }^{3}$

\section{A saúde pública como política social}

Os estudos marxistas na área da política social tiveram grande desenvolvimento nos anos 70, vinculados a um amplo renascimento da teoria

1. Alguns trabalhos importantes que se ajustam mais ou menos ao esquema da "análise cultural" incluem os de Adam [ADAM B., "The State, Public Policy and AIDS Discourse". Contemporary Crises 13, 1989], Mort [MORT F., Dangerous Sexualities: Medico-Moral Politics in England since 1830. Londres, Routledge and Keagan Paul, 1987], Patton [PATTON C., Sex and Germs: The Politics of AIDS. Montreal, Black Rose, 1986], Padgug [PADGUG R., "Gay Villain, Gay Hero: Homosexuality and the Social Construction of AIDS", in K. Peiss e C. Simmons com R. Padgug, Passion and Power: Sexuality in History. Filadélfia, Temple University Press.], Tesh [TESH S., Hidden Arguments: Political Ideology and Disease Prevention Policy. New Brunswick, Rutgers University Press, 1988.] Watney [WATNEY S., "Taking Liberties: An Introduction", in E. Carter e S. Watney (eds.) Taking Liberties: AIDS and Cultural Politics. Londres, Serpent's Tail, 1989] e Weeks [WEEKS J., Sexuality and Its Discontents. Londres, Routledge, 1985].

2. TESH S., Hidden Arguments: Political Ideology and Disease Prevention Policy. New Brunswick, Rutgers University Press, 1988.

3. Veja-se Fee Fox [FEE E. e FOX D. (eds.) AIDS: The Burdens of History. Berkeley, University of California Press, 1988], uma excelente coletânea de artigos que examinam criticamente a história da saúde pública à luz da AIDS. 
marxista do Estado. $\mathrm{O}$ foco de interesse da crítica à política social afastou-se, porém, do marxismo ao longo dos anos 80. Uma prova dessa mudança temática é o predomínio das "teorias da cultura" na literatura sobre a AIDS e a virtual invisibilidade do marxismo nessa área.

\section{A AIDS e a "teoria da cultura"}

A obra de Michel Foucault foi a que exerceu maior influência sobre as análises da AIDS dentro da perspectiva da "teoria da cultura". Uma das maiores contribuições de Foucault à teoria social foi sua concepção de um poder penetrante e difuso no interior das relações sociais. "O póder está em toda parte: não porque tudo açambarque, mas porque procede de todos os lugares." ${ }^{4}$ Essa concepção teve a enorme capacidade de ampliar nossa compreensão dos modos de dominação que ultrapassam a coerção bruta e se estendem ao âmbito mais largo das "tecnologias do poder", disciplinadoras das pessoas através de diferentes modalidades de acumular conhecimento sobre elas (como o exame minucioso e a classificação). $O$ "olhar médico", por exemplo, combina a organização da percepção (audição, tato, visão) e modos específicos de expressão que permitem, pela primeira vez, a elaboração de um "discurso científico sobre o indivíduo", constitutivo e estruturante da experiência. ${ }^{5}$

Essa construção da experiência, essa modalidade de saber, reproduz as estratégias de poder, as maneiras de conhecer. Há "um incessante vaivém entre as formas de sujeição e os esquemas de conhecimento", diz Foucault. ${ }^{6}$ Com isso, o Estado é deslocado da condição de "posição privilegiada a ser conquistada"; ele não "tem toda essa unidade, essa individualidade, essa rigorosa funcionalidade, nem, para falar francamente, toda essa importância", acrescenta Foucault. ${ }^{7}$

Essa concepção teve profunda influência sobre os estudos críticos recentes a respeito da saúde pública e da AIDS. As atenções se voltavam para o modo como a resposta à AIDS e a outras questões sanitárias se organizavam em torno de certos conceitos nucleares como saúde, comunidade, gênero e sexualidade, e não na maneira como são organizados pelos Estados capitalistas através da teoria e da prática da saúde pública.

4. FOUCAULT M., The History of Sexuality, v. 1, Nova York, Vintage Books. (Traduçāo brasileira, História da sexualidade), 1980, p. 93.

5. FOUCAULT M., The Birth of the Clinic. Nova York, Pantheon. (Traduçäo brasileira, O nascimento da clínica. Rio de Janeiro, Forense Universitária, 1977, pp. xiv, 163, 196-99).

6. FOUCAULT M., The History of Sexuality, op. cit., 1980, p. 98.

7. FOUCAULT M., "On Governmentality". Ideology and Consciousness, $\mathrm{n}^{2}$ 6, 1979, p. 20. 
Com seu importante trabalho sobre a sexualidade, Weeks ${ }^{8}$ abriu o caminho para a maioria dessas análises. Para ele, ${ }^{9}$ a sexualidade é o "produto de um grande número de tradições e práticas sociais autônomas e interdependentes", dentre as quais são particularmente importantes "as categorias, conceitos e linguagens que organizam a vida sexual”. Ele afirma que as respostas à AIDS podem ser vistas como um pânico moral que se fundamenta nas mudanças na sexualidade desde a década de 60 , além do crescimento mais recente da nova direita. Em síntese, era iminente uma crise na constituição da sexualidade, e a AIDS foi a forma como ela se processou. "Em certo sentido, portanto, já havia um problema imanente esperando por uma solução simbólica." 10 Assim, entende-se a reação à AIDS como uma crise cujo significado se localiza principalmente nos discursos sobre a sexualidade.

Uma vez que as respostas à AIDS são definidas nesse plano, a atividade do Estado passa a ser vista como uma das muitas formas de reagir a uma crise de significado na sexualidade. Como argumenta Watney, ${ }^{11}$ "o Estado evidentemente reage a esta situação, mas não é sua origem”. Nesta perspectiva, a política social não regula de fora, mas repercute e ressoa juntamente com as modalidades de saber que constituem o indivíduo. Portanto, "a aceitação da política social é uma decorrência do próprio desejo". ${ }^{12}$

O Estado tem um papel nesse processo, mas é um papel secundário e reativo. A visão de que o poder é penetrante, difuso e discursivo rejeita a centralidade teórica do Estado. Como uma instância de análise, o Estado funciona principalmente como o local do confronto, organização, filtragem e legitimação dos discursos provenientes da "sociedade civil". Essa concepção do Estado é compatível com o "pluralismo radical" que se desenvolveu no campo da "teoria dos novos movimentos sociais".

$\mathrm{O}$ argumento central dessa teoria é o de que a complexidade da sociedade (capitalista) contemporânea produz uma diversidade de movimentos de resistência que não podem ser adequadamente compreendidos pela perspectiva marxista, que privilegia a política de classes. Há necessidade de uma política "pluralista radical" que unifique as diferentes lutas sem

8. WEEKS J., Sexuality and Its Discontents. op. cit.

9. WEEKS J., op. cit, p. 6-7.

10. WEEKS J., “AIDS: The Intellectual Agenda”, in P. Aggleton, G. Hart e P. Davies (eds), AIDS: Social Representations, Social Practices. Londres, The Falmer Press, 1989, p. 10.

11. WATNEY S., "The Spectacle of AIDS", in D. Crimo (ed.)AIDS: CulturalAnalysis, Cultural Activism. Cambridge, MIT Press, 1988, p. 75.

12. WATNEY S., "The Spectacle of AIDS", op. cit. 
comprometer sua autonomia ou violar sua especificidade. ${ }^{13}$ Se esse ponto de vista retoma a discussão de Foucault ${ }^{14}$ a respeito da "pluralidade de resistências", ele se baseia, mais concretamente, no pós-marxismo desenvolvido por um grupo de pessoas que se envolveram, e depois rejeitaram, em parte ou na totalidade, a teoria e a prática marxistas. ${ }^{15}$

Esse conjunto de concepções políticas teve grande influência nos estudos sobre a AIDS e a saúde pública realizados na óptica da "teoria da cultura". O marxismo (ao menos em sua forma "reducionista" mais persistente) é recusado por Mort, ${ }^{16}$ Watney $^{17}$ e Weeks. ${ }^{18}$ Ao contrário, esses autores defendem novas formas de concepção política, por exemplo aquelas que Watney descreve: ${ }^{19}$

"Isso implica o desenvolvimento de uma política simbólica criativa que traduza questões complexas em imagens imediatamente compreensíveis, com as quais os públicos possam facilmente identificar sua própria experiência social de frustração diante da burocracia, da corrupção, da política partidária etc."

É possível criticar essa visão da "política cultural" por seu idealismo e voluntarismo (veja-se, por exemplo, Palmer) ${ }^{20} \mathrm{O}$ mais importante, nesse caso, é considerar a teoria do Estado que essa política implicitamente contém. Como afirma Woods (1990, p. 78-9), o novo pluralismo "radical", na realidade, reproduz a velha teoria pluralista do Estado:

"Segundo o antigo e o novo pluralismo, os 'grupos de interesse' ou as 'identidades' são independentes mas iguais, ou pelo menos equivalentes; são mais plurais do que diferentes. E nossa democracia é uma espécie de mercado onde esses interesses e identidades se encontram e entram em competição."

Quando os “teóricos da cultura” examinam o Estado, tendem a vê-lo como um corpo neutro, cujas políticas são modeladas pelos interesses e pressões

13. MORT F., Dangerous Sexualities: Medico-Moral Politics in England since 1830, op. cit., 1987, p. 219; WEEKS J., Sexuality and Its Discontents, op. cit, 1985, pp. 242-5, 253-5.

14. FOUCAULT M., The History of Sexuality, op. cit., 1980, p. 96.

15. CALliNICOS A., Against Postmodernism: A marxist Critique. Nova York, St. Martin's Press, 1990.

16. MORT F., Dangerous Sexualities: Medico-Moral Politics in England since 1830. op. cit., 1987, p. 6.

17. WATNEY S., Policing Desire. Mineápolis, University of Minnesota Press, 1987, p. 64.

18. WEEKS J., Sexuality and Its Discontents. op. cit., 1985, pp. 253-5.

19. WATNEY S., "Taking Liberties: An Introduction", in E. Carter e S. Watney (eds.) Taking Liberties: AIDS and Cultural Politics, Londres, Serpent's Tail, 1989a, p. 51.

20. PALMER B., "The Eclipse of Materialism: Marxism and the Writing of Social History in the 1980s". Socialist Register 1990. 1990, p. 131. 
de uma multiplicidade de grupos (profissões, lobbies organizados, comunidades etc.). Mort é quem mais claramente sugere esse ponto de vista, ${ }^{21}$ ao argumentar que a decisão de regular a sexualidade através da legislação penal, no final do século XIX, "absolutamente não se originou no Estado, no seu sentido restrito, mas nos grupos puristas e feministas..." O Estado aparece com mais proeminência nos trabalhos históricos de Mort, mas é pensado como reagindo aos grupos que "definiram novas representações do sexo".22

"O Estado foi um parceiro relativamente subordinado e muitas vezes passivo no diálogo com os puristas e as feministas. Ele articulou as várias forças políticas existentes na sociedade civil." ${ }^{23}$

Embora as teorias da cultura tenham contribuído com extraordinários insights para a agenda moral que orienta as respostas à AIDS, elas o fizeram com base em teses que sistematicamente se afastavam da análise teórica do Estado capitalista como o ponto de concentração do poder social materialmente radicado nas relações de classe predominantes. Neste artigo, procuro desenvolver essas concepçōes, articulando-as ao contexto da teoria marxista do Estado.

\section{Saúde pública e Estado}

O primeiro ponto a assinalar é que a saúde pública moderna, desde o início, se identificou com o Estado. De fato, a própria concepção de "saúde pública" centra-se no Estado, explícita ou implicitamente. Ela nāo só privilegia o Estado como a única agência capaz de criar uma sociedade sadia, mas também compreende os parâmetros da comunidade através da perspectiva estatal.

Duas características distinguem a saúde pública no campo da saúde: uma concentração de prevenção e uma abordagem que acentua a comunidade em vez do indivíduo. Os programas preventivos de saúde pública visam a reduzir a incidência da doença através da melhoria das condiçōes do meio ambiente, da redução dos comportamentos de risco, da vacinação contra moléstias e do uso do isolamento para evitar a transmissão de doenças. Essas atividades de caráter preventivo são realizadas principal-

21. MORT F., Dangerous Sexualities: Medico-Moral Politics in England since 1830. Londres, Routledge and Keagn Paul, 1987, p. 126.

22. MORT F., op. cit., p. 209.

23. MORT F., Purity, Feminism and the State: Sexuality and Moral Politics 1880-1914, in M. Lanagan e B. Schwartz (ed.), Crises in the British State. Londres, Hutchinson, 1985, p. 210. 
mente por programas estatais nos níveis local, regional e nacional. Em termos de autoridade legal, capacidade financeira e responsabilidade ideológica, apenas o Estado está equipado para cumprir tais programas na sociedade capitalista.

A orientação da teoria e da prática da saúde pública centrada no Estado não se deve à consideração pragmática de quem está em posição de implementar tais programas. A saúde pública encara as questões da saúde e da doença no plano da sociedade, e não do indivíduo. Um reformador da saúde pública inglesa escreveu em 1870: “... a higiene lida com a humanidade, mas não com indivíduos isoladamente, e sim com as massas..."(Guy, citado por Lillienfeld. ${ }^{24}$ ) Beauchamp ${ }^{25}$ e Friedman ${ }^{26}$ referemse a isso como a tradição comunitária da saúde pública.

Nessa tradição comunitária, é básica a idéia de que o bem-estar da comunidade depende da subordinação dos interesses do indivíduo a algum tipo de coletividade (veja-se Porter e Porter. ${ }^{27}$ ) Esse aspecto da saúde pública foi elogiado pelos críticos da instituição médica. Bevan, ${ }^{28} \mathrm{O}$ artífice parlamentar do Serviço Nacional de Saúde da Inglaterra, assim escreveu a respeito dos agentes da saúde pública:

"...todo o significado de sua contribuição consiste na insistência em que as reivindicações do indivíduo devem se subordinar aos códigos sociais que têm o bem-estar coletivo como meta, independentemente da extensão em que isso frustra a ganância individual."

O Estado era a agência através da qual a subordinação devia ser garantida. A identificação do bem-estar coletivo com o Estado capitalista está implícita nessa formulação. A saúde pública entende a comunidade através do Estado, e assim as características e limites do Estado se tornam seus pressupostos.

Desde o início, a saúde pública se identificou com o Estado. Em sua forma moderna, ela surgiu no mundo de língua inglesa a partir da obra de Edwin Chadwick e da Comissão da Lei dos Pobres, na Inglaterra, que visava a atenuar a miséria e a dependência da assistência social. A Reforma

24. LILLIENFELD A. e LILLIENFELD D., "Epidemiology and the Public Health Movement: A Historical Perspective". Journal of Public Health Policy 3(2), 1982, p. 145.

25. BEAUCHAMP D.E., "Community: The Neglected Tradition of Public Health". Hastings Center Report 15(6), 1985.

26. FRIEDMAN E., "Your Own Kind: AIDS and the Communitarian Ethic", in J. Griggs (ed.), AIDS: Public Policy Dimensions. Nova York, United Hospital Fund of New York, 1987.

27. PORTER D. e PORTER R., "The Enforcement of Health: The British Debate", in E. Fee e D. Fox (eds.). AIDS, 1988.

28. BEVAN A., In Place of Fear. Londres, Heineman, 1952, p. 73. 
da Lei dos Pobres, de 1834, devia sustar o que se considerava como miséria voluntária entre as pessoas fisicamente capazes e forçar os trabalhadores a entrar no mercado de trabalho, tornando punitivos e insuficientes os benefícios assistenciais. A saúde pública foi concebida como uma extensão dessa abordagem, diminuindo a miséria involuntária (isto é, entre os doentes e dependentes), combatendo as condições que geravam a doença e a morte e lançavam as pessoas na assistência social. ${ }^{29,30}$

Historicamente, a saúde pública nasceu da atividade estatal, seus objetivos e métodos foram modelados pelas prioridades da política social. ${ }^{31}$ Frazer ${ }^{32}$ descreve a saúde pública como "Uma ação do Estado que visa a influenciar positivamente a saúde da comunidade..." Ela envolve, então, o uso do poder do Estado para evitar moléstias e enfermidades através da modificação dos comportamentos e das condições sociais que promovem a doença. Até mesmo as atividades sanitárias de iniciativa voluntária tendem a ser determinadas, financiadas e controladas pelo Estado (por exemplo, a campanha educativa dirigida pela Associação Canadense de saúde pública).

\section{Estado e comunidade}

Uma das grandes contribuições dos estudos sobre a AIDS feitos sob a óptica da "teoria da cultura" tem sido a de chamar a atenção para o modo como as respostas a essa doença se organizam em torno de concepções estreitas e excludentes da comunidade, em oposição a noções mais pluralistas e inclusivas (veja-se, a esse respeito, Patton; ${ }^{33}$ Watney ${ }^{34}$ ). Esses estudos tendem a situar o conceito de comunidade no plano das idéias; em vez disso, argumentarei que a comunidade está materialmente enraizada nas relações entre a sociedade e o Estado capitalista.

A saúde pública concebe a "comunidade" sobretudo em termos políticos, como a população que pertence a um determinado Estado. E uma

29. FINER S. E., The Life and Times of Sir Edwin Chadwick, Londres, Methuen, 1952, pp. 147-57.

30. CHADWICK E., The Financial Value of Sanitary Science. Londres, 1987.

31. sso foi retratado por Rosen [ROSEN G., A History of Public Health. Nova York, MD Publications, 1958 , pp. 209, 224-5] como um acidente ligado ao subdesenvolvimento relativo da ciência médica na época. Eu diria, contudo, que a teoria e a prática da saúde pública continuaram a orientar-se para o Estado apesar do crescimento da ciência médica no século XX.

32. FRAZER W.M., A History of English Public Health 1834-1939. Londres, Balliere, Tindall and Cox, 1950 , p. 1.

33. PATTON C., Sex and Germs: The Politics of AIDS. Montreal, Black Rose, 1986, p. 58-9.

34. WATNEY S., "AIDS, Language and the Third World”, in E. Cater e S. Watney (eds.), TakingLiberties, 1989 b, p. 190. 
comunidade definida pelas fronteiras de jurisdiçāo da saúde pública ligadas aos governos local, regional ou nacional. A saúde pública concentra-se na saúde das nações ${ }^{35}$ ou de subseçōes politicamente delimitadas, como províncias ou municipalidades.

Os funcionários encarregados de proteger a saúde da populaçāo de uma jurisdição particular cumprem sua tarefa, em parte, reforçando as fronteiras da comunidade contra a invasão da doença (ou daqueles que são considerados seus portadores). Um relato histórico dos cuidados sanitários em Ontário ${ }^{36}$ diz: "Saúde pública também significava manter a doença longe de Ontário." A atividade de "manter a doença longe" tem a consequêencia política de construir a categoria "outros" como uma ameaça à saúde, “à saúde” do "público".

Esse entendimento dos "outros" através da identificação com o Estado é complementado por uma interpretação específica do "nós", os membros da comunidade. Os Estados capitalistas sempre entenderam as comunidades sob sua guarda em termos de uma categoria especificamente histórica de "população", como um conjunto de equivalentes indiferenciados, ligados entre si por sua relação com um determinado Estado. ${ }^{37}$ Esse conceito de cidadania encontra raízes materiais no caráter do mercado de trabalho capitalista, onde compradores e vendedores da força de trabalho se encontram como equivalentes na esfera da troca de mercadorias. Marx ${ }^{38}$ afirmava que essa conexão cria uma relação de igualdade formal, "porque cada um entra em relaçāo com o outro como mero proprietário de mercadorias e todos trocam, entre si, equivalentes". Esses equivalentes são gradualmente incorporados a uma cidadania universal através do processo histórico de formação do Estado, que o insere de modo cada vez mais profundo no interior da sociedade. ${ }^{39} \mathrm{~A}$ concepção de uma cidadania indiferenciada transfere-se para o terreno da saúde pública na forma de uma "população em geral", conceito implicitamente normativo. ${ }^{40}$

Assim, a saúde pública concebe a comunidade pela óptica do Estado. O resultado é uma construçāo da idéia de fomento da saúde como atividade de regulação das ameaças externas e de promoção cultural de determina-

35. CHADWICK E., The Financial Value of Sanitary Science. Londres, 1887.

36. ONTARIO. Ministry of Health Annual Report. Toronto, Provincia de Ontário, 1982, p. 46

37. KAY G., e MOTT J., Political Order and the Law of Labour. Londres, Macmillan, 1982, p. 91.

38. MARX K., Capital, v. 1. Moscou, Progress, 1954, p. 172.

39. CORRIGAN P. e SAYER D., The Great Arch: English State Formation as Cultural Revolution. Oxford, Basil Blackwell, 1985.

40. WATNEY S., "The Spectacle of AIDS", in D. Crimo (ed.)ADDS: CulturalAnalysis, CulturalActivism. Cambridge, MIT Press, 1988, p. 73. 
dos padrōes de comportamento "normal saudável”. Dessa maneira, a saúde pública concentra uma grande atenção nas questões da imigração, da assimilação cultural, dos valores da família e da regulação do sexo.

\section{Limites do Estado}

A identificação entre as condições de saúde da população e o Estado acarreta uma outra consequiência de forte impacto sobre a teoria e a prática da saúde pública. A comunidade que é objeto de sua ação tem um formato particular, é dominada por um certa estrutura de relaçōes sociais, que se tornam os pressupostos de toda atividade. Clarke ${ }^{41}$ escreveu a respeito do Estado capitalista que:

"Tanto sua existência como força material quanto suas formas de intervençāo social subordinam-se à necessidade de garantir a reprodução ampliada das relações de produção capitalistas."

Como aspecto do poder estatal, a saúde pública se limita portanto, a reproduzir a comunidade sadia, reproduzindo uma estrutura particular de relaçōes sociais. Em certos momentos, os agentes da saúde pública tiveram condições de defender - e, de fato, o fizeram - soluçōes que extrapolavam esses limites. mas não puderam colocá-las em prática. Alguns recomendavam soluçōes que ultrapassavam de longe sua esfera de competência. O Medical Officer of Health (Secretário de Estado de Saúde) de Toronto, por exemplo, terminou um artigo fazendo um apelo, em tom bastante radical, em defesa do pleno emprego (masculino) e do salário mínimo:

"Mas nessa nação democrática, parece-nos ser um fato bastante contraditório que 51 multimilionários detenham $1 / 3$ de toda a riqueza nacional, enquanto outros 450 possuem cerca de $9 / 10$ do total da riqueza... No interesse dos futuros destinos desta nação deveria ser possível que todo homem recebesse um salário capaz de lhe proporcionar, e a seus filhos, as condiçōes de habitação, alimentação e vestuário necessárias ao desenvolvimento de suas melhores e mais elevadas potencialidades. " 42

Os agentes da saúde pública estavam em posição de reivindicar algumas dessas mudanças, mas, evidentemente, não foram capazes de torná-las

41. CLARKE S., "State, Class Struggle and the Reproduction of Capital". Kapitalistate 10/11. 1982, p. 123.

42. HASTINGS C., "The Modern Conception of Public Health Administration". Conservation of Life 3 (3\&4), 1917, p. 90. 
realidade. Em sua atividade prática, esses agentes tenderam a concentrar esforços no que denominaremos adiante "influências controláveis". A importância desse enfoque pragmático foi a de excluir questões mais amplas, relativas ao elo entre as condições sociais e a saúde no cerne da estrutura oficial da saúde pública. Isso se revelou particularmente verdadeiro no que diz respeito às relações entre pobreza e doença. Os agentes da saúde pública tenderam a negar que a pobreza, em si, fosse uma das principais causas da doença. Em vez disso, identificaram fatores "controláveis" secundários, que procuraram remover.

A saúde pública conquistou, então, um conjunto específico de políticas através de sua identificação com o Estado capitalista. Ela oferece um excelente exemplo daquilo que Marx e Engels ${ }^{43}$ denominaram de "comunidade ilusória” embutida no Estado capitalista. ${ }^{44}$ A reprodução de uma comunidade sadia significava reproduzir uma classe operária suficientemente sadia através do sistema da família. Agentes da saúde pública do início do século XIX afirmavam isso com todas as letras:

"Hoje não há dúvida de que o efeito direto sobre o que chamamos de capacidade de trabalho do país é a força motivadora da ação que visa a salvar as vidas dos cidadãos, as fontes do poder, seja ele para a defesa nacional, seja para o progresso econômico."

Os agentes da saúde pública reconheciam, como exigência básica da indústria, que "os produtores do trabalho, a família, a escola e a comunidade deveriam ser mantidos em alto grau de eficiência". ${ }^{45}$ Com isso, as condições de saúde da população contribuíam para o que um funcionário inglês argutamente chamou de "a arte da formação da cidadania". ${ }^{46} \mathrm{E}$ isso exigia a limitação dos interesses de classe particulares, em benefício dos "interesses comuns", corporificados na saúde pública e no Estado. Considerava-se ser do interesse de todos que a classe trabalhadora obtivesse os recursos (salários adequados, habitação, alimentação etc.) e a orientação (supervisão e educação) necessários para que se mantivesse saudável e satisfeita..$^{47,48}$ Para se alcançar esse resultado, era necessário, como disse um funcionário da época, que: “... a terra, o trabalho e o capital se

43. MARX K. e ENGELS F., The German Ideology. Nova York, International, 1970, p. 107.

44. ABRAMS P., "Some Notes on the Difficulty of Studying the State". Journal of Historical Sociology, 1(1), 1988.

45. SMITH W.G., "Psychology and Public Health". Public Health Journal 9(3), 1918, p. 107.

46. BUSHNELL F., "The Appointment of Ministers of Health". Journal of the Royal Sanitary Institute 24(3), 1903, p. 297.

47. PATTIN H.C., "On the State Standardization of National Life". Public Health 23(2), 1909.

48. HASTINGS C., "Democracy and Public Health Administration". Public Health Journal 10(3), 1919. 
juntassem num vínculo de amor". ${ }^{49}$ Evidentemente, só o Estado podia consagrar essa convivência, na medida em que encarnava os interesses gerais da nação.

O argumento deste artigo não depende, porém, do reconhecimento explícito por parte dos agentes da saúde pública de seu papel na reprodução das relações capitalistas. Em vez disso, procuro demonstrar os modos como a identificação entre saúde pública e Estado têm modelado diversas campanhas sanitárias durante o século XX, desde a tuberculose até a AIDS. Será dada ênfase particular à reconstituição das maneiras como a saúde pública funcionou como reforço das fronteiras e normas da comunidade centrada no Estado, enquanto operava pragmaticamente dentro dos limites políticos e econômicos da atividade estatal.

\section{A nova higiene: $1900-1920$}

Os historiadores da saúde pública encaram o final do século XIX e início do século XX como um importante período de transição. ${ }^{50,51,52}$ A antiga concepção do sanitarismo do século XIX foi substituída pela nova higiene. Essa mudança de orientação se processou em dois níveis. No plano prático, o campo principal da intervenção da saúde pública transferiu-se das condições sanitárias do meio físico para os padrões de higiene do lar. No plano teórico, a base científica da saúde pública se consolidou (ao menos aos olhos de alguns contemporâneos) através da aceitação final das teorias do germe na transmissão de doenças.

Os agentes da saúde pública do início deste século se percebiam como líderes de uma nova era de política social, que promoveria saúde e prosperidade pela extensāo do alcance do Estado na vida cotidiana dos cidadãos. Eles acreditavam estar num momento de ruptura científica, de rápida inovação nas políticas concretas e de expansão geral dos programas de ação. O Secretário da Junta Provincial de Saúde de Ontário, comentando o crescimento do interesse pela saúde pública naquela época, perguntou: "Não estaremos asșistindo ao início de uma era em que a saúde pública se

49. CANADÁ, "Report of the Chief Medical Officer's in Canada. Department of the Interior. Annual Report (Otawa, King's Printer), 1915, p. 56.

50. FRAZER W. M., A History of English Public Health 1834-1939. Londres, Balliere, Tindall and Cox, 1950, pp. 239-266.

51. ROSEN G., A History of Public Health. Nova York, MD Publications, 1958, pp. 294-332.

52. ASHTON J. e SEYMOUR H., The New Public Health. Milton Keynes: Open University Press, 1988, p. 17. 
tornará, tanto na prática quanto na teoria, a maior de todas as questōes públicas?"53

Os problemas da saúde pública na era da nova higiene eram a tuberculose, a mortalidade infantil e as doenças sexualmente transmissíveis. Os programas de ação para esses problemas tinham muitos temas comuns, que podem ser associados às política estatais de saúde pública. Desenvolveram-se novas estratégias de saúde comunitária para evitar a disseminação de infecçōes através da fixação e do reforço de fronteiras. Conferiu-se grande ênfase às campanhas educativas de combate aos aspectos morais $\mathrm{e}$ comportamentais da doença, dentro dos limites do poder estatal.

Uma importante linha de continuidade perpassa os conceitos da nova higiene do início deste século e os da saúde pública contemporânea. Os principais esteios da campanha contra a AIDS podem ser descobertos nas campanhas anteriores contra a tuberculose, a mortalidade infantil e as doenças sexualmente transmissíveis. Nesta seção examino as primeiras estratégias, desenvolvidas no período 1900-1920, e na seçāo seguinte mostro a maneira como elas influenciaram as campanhas atuais.

\section{A política da saúde comunitária}

Já me referi acima ao fato de que um dos aspectos centrais da saúde pública foi seu reforço às fronteiras, politicamente definidas, da comunidade. $O$ objetivo era cortar as rotas de transmissão de doenças pelo estabelecimento de algum tipo de fronteira entre pessoas infectadas e pessoas sãs (veja-se em Musto). ${ }^{54}$ Historicamente, esse objetivo foi alcançado pela definição de cordōes de isolamento entre as comunidades, através da inspeção de fronteiras, que visava a restringir a entrada da infecção, bem como pela identificação e confinamento de pessoas infectadas que moravam na comunidade. 55

$\mathrm{Na}$ era da nova higiene, as estratégias de reforço de fronteiras assumiram duas formas. Primeiro, introduziram-se novos planos de controle da entrada de imigrantes. Segundo, modificou-se o método tradicional da quarentena para confinar pessoas infectadas na comunidade, à luz das

53. ONTARIO, Provincial Board of HealthAnnualReport. Toronto, L. K. Cameron/A. T. Wilgress, 1912, p. 9.

54. MUSTO D., "Quarantine and the Problem of AIDS", in E. Fee e D. Fox (eds.), AIDS: The Burdens of History. Berkeley, University of California Press, 1988.

55. SLACK P., "Responsess to Plagues in Early Modern Europe: The Implications of Public Health". Social Research 55(3), 1988. 
teorias dos germes, produzindo-se o que Hill"s6 chamou de "nova quarentena".

No Canadá do início do século XX, a questão das fronteiras comunitárias interligava-se com os problemas da imigração. Os imigrantes eram vistos como portadores potenciais de doenças, trazendo as infecções quando entravam no país. Em segundo lugar, os imigrantes que se estabeleceram no Canadá (especialmente nos centros urbanos) eram vistos como uma ameaça à saúde por causa das condições de superpopulação e dos hábitos sociais. Os agentes de saúde pública envolveram-se, portanto, numa dupla estratégia de controlar a entrada dos imigrantes, tidos como potencialmente ameaçadores à saúde, enquanto desenvolviam um trabalho de educação e assimilação dos que se estabeleciam no Canadá. ${ }^{57}$

A inspeção médica, introduzida em 1902, realizou o trabalho de controle dos imigrantes. À inspeção acrescentaram-se medidas de quarentena, existentes desde a década de 1830 , para manter sob custódia pessoas ou barcos que entravam no país e traziam moléstias infecciosas específicas. A inspeção médica consistia de um rápido exame dos imigrantes, à medida que eles entravam no país, para verificar se eram portadores de algum problema dentre uma série de deficiências físicas, mentais e morais. No Canadá, a inspeção era chefiada por um dos mais importantes funcionários do setor de saúde pública do país, P. H. Bruce, o primeiro secretário da Junta Provincial de Saúde de Ontário. A inspeção era considerada uma prioridade para conservar a nação sadia.

A inspeção médica era complementada por atividades de promoção da assimilação dos imigrantes no Canadá. Agentes sanitaristas procuravam "canadianizar" os imigrantes, assegurando sua assimilação cultural e social (veja-se em Clarke $^{58}$ e Canadás ${ }^{59}$ ). Isso deveria ser realizado pelos departamentos locais de saúde pública, que discutirei adiante. A "nova quarentena", destinada a evitar a difusão de doenças por pessoas infectadas dentro da comunidade, complementava a inspeção médica, voltada para manter longe a doença. Durante muito tempo a quarentena tinha sido um elemento essencial das estratégias de saúde. Os praticantes da nova

56. HILL H. W., The New Public Health. Nova York, Macmillan, 1920, pp. 191-2.

57. Essa discussão foi extraída de Sears (1990). Veja também Roberts [ROBERTS, B. From Whence They Came. Otawa, University of Ottawa Press, 1988] e Bator [BATOR, P. Saving Lives on the Wholesale Plan: Public Health Reform in the City of Toronto, 1900-30. Tese de Doutorado, Universidade de Toronto, 1979] para discussōes acerca da saúde pública e dos controles da imigração neste período.

58. CLARKE C.K., "Immigration". Public Health Journal 10(10), 1919, p. 441.

59. CANADA, "Report of the Chief Medical Officer" in Canada. Department of Immigration and Colonization. Annual Report. (Otawa, King's Printer), 1919, p. 28. 
higiene criticavam muito as técnicas tradicionais de quarentena, que comparavam com as antigas abordagens sanitaristas da saúde pública. Ao invés, eles pregavam uma nova abordagem dessa estratégia.

O novo modelo de quarentena não é um método genérico, que engloba, às cegas e indiscriminadamente, tanto os doentes quanto os sãos, tanto $O$ que é nocivo quanto o que não é. Esse novo modelo exige um conhecimento minucioso e preciso, que se aplica com cuidado e paciência, e não usa a pura força: ${ }^{60}$

" $O$ 'saber minucioso e preciso', associado à nova quarentena, provém das teorias do germe, que permitiram estabelecer uma determinação mais nítida dos estados de infecção. A nova quarentena visava identificar os infectados e interromper diretamente as rotas da infecção que os cercavam. A meta era manter o infectado não em uma situação antiquada de quarentena, mas sob controle, de modo que suas emissões não se transmitissem aos outros..." 61

O novo método acentuava a utilização da higiene doméstica na prevenção da difusão de infecções. O objetivo dessa estratégia era separar setores doentes e sadios da população pela construção de um cordon sanitaire (“cordão sanitário") dentro de cada domicílio através do trabalho doméstico das mulheres. A idéia era interromper as vias de transmissão entre pessoas sadias e doentes. Um dos teóricos da Nova Higiene assim descreveu a estratégia:

"O governo deve atacar as fontes e as rotas públicas da infecção. As mulheres devem combater as rotas privadas. Os homens devem suportar ambos os métodos para o bem das mulheres e das crianças". ${ }^{62,63,64}$

Essas idéias colocaram o reforço do sistema familiar no centro do projeto de saúde pública. Nas palavras do chefe do serviço de enfermagem da saúde pública de Toronto, "a unidade do trabalho em saúde é a família e não o indivíduo". ${ }^{65} \mathrm{Em}$ geral, os agentes dos serviços de saúde pública consideravam a família como uma instituição social e ideológica decisiva,

60. HILL H. W., The New Public Health. Nova York, Macmillan, 1920, pp. 191-2.

61. HILL H. W., op. cit., 1920

62. HILL H. W., op. cit., 1920.

63. DEHLI K., Women and Class: The Social Organization of Mother's Relations to Schools in Toronto, 1915 to 1940 . Tese de Doutorado. University of Toronto, 1988.

64. DEHLI K., "Creating a Dense and Intelligent Community: Local State Formation in Early 19th. Century Upper Canada". Journal of Historical Sociology 3(2), 1990.

65. DYKE E., "Tuberculosis in Toronto". Public Health Journal 4(7), 1913, p. 403. 
“...a família constitui a unidade da sociedade, todo o nosso código moral e social ergue-se sobre essa fundação". ${ }^{66}$

De modo mais específico, esses funcionários enfatizavam a importância da família como unidade doméstica, o lugar da reprodução cotidiana e geracional: "...a unidade da cidade é o lar; e na medida em que cada um de nós tornar nossa casa e seu meio ambiente saudáveis estaremos todos contribuindo com nosso quinhão para a saúde da comunidade em que vivemos e do país em geral." $" 7$

A melhoria das condições de saúde do lar era vista como um elo crucial do cordão sanitário que devia proteger os sadios contra os infectados, mecanismo central para melhorar os padrões gerais de saúde. Esse resultado deveria ser obtido através da regulação do trabalho executado principalmente pelas mulheres dentro do lar. Comó escreveu Plumptre, 68 "a conservação da vida humana é o dever imediato das mulheres deste país". Tratava-se de fazer as mulheres cumprirem "seu dever" com mais eficiência.

Isso seria obtido através de programas de visita aos lares, distribuindo conselhos e instruçāo sobre a execução das tarefas domésticas, por ocasião, por exemplo, da ocorrência de um diagnóstico de tuberculose no domicílio (por enfermeiras dos serviços de tuberculose ou da saúde pública), do nascimento de uma criança (por visitadoras ou enfermeiras da saúde pública), ou a descoberta de uma criança em idade escolar doente ou faltando à escola, por enfermeiras escolares (veja-se em Davin; ${ }^{69,70}$ Sutherland $;{ }^{71}$ Dehli $^{72}$ ). O objetivo das visitas era "manter um controle amistoso" sobre os pacientes em casa, "instruir por aconselhamento e advertência". ${ }^{73}$ Mais adiante discuto essa atividade educacional.

$\mathrm{Na}$ teoria e na prática da saúde pública, a "nova quarentena" estava inteiramente vinculada ao projeto de "nacionalização" do trabalho doméstico das mulheres. Baseava-se na premissa de que as mulheres executavam trabalho doméstico para a família enquanto os homens realizavam trabalho

66. ADAMI J.G., "The Policy of the Ostrich". Canadian Medical Association, 1919, p. 289.

67. CONSERVATION OF LIFE. "Canada's Need". Conservation of Life 5(2), 1919, p. 25.

68. PLUMPTRE H.P., "The National Council of Women and Conservation". Commission of Conservation Annual Meeting, 1914, p. 28

69. DAVIN A., "Imperialism and Motherhood". History Workshop Journal 5, 1978.

70. EHRENREICH B. e ENGLISH D., For Her Own Good. Garden City, N.Y., Anchor Books, 1979.

71. SUTHERLAND N., Children in English Canadian Society. Toronto, Toron to University Press, 1979.

72. DEHLI K., Women and Class: The Social Organization of Mother's Relations to Schools in Toronto, 1915 to 1940 . Tese de Doutorado. University of Toronto, 1988; DEHLI, K. "Creating a Dense and Intelligent Community: Local State Formation in Early 19th. Century Upper Canada". Journal of Historical Sociology 3(2), 1990.

73. ONTARIO, Provincial Board of Health Annual Report, op. cit, 1904, p. 84. 
assalariado para ter acesso aos recursos necessários. Essa divisão do trabalho deveria agora ser controlada pelos agentes da saúde pública, o que se considerava como uma atividade neutra e do interesse de toda a nação. Como escreveu Helen MacMurphy, funcionária da saúde pública, em uma publicação destinada às mãos de recém-nascidos:

"Nenhum serviço nacional é maior ou melhor do que o trabalho da mãe em seu próprio lar. A mulher é a primeira servidora do Estado."

Outro aspecto desse cordāo sanitário doméstico era um regime de regulação do sexo, ${ }^{74}$ que girava principalmente em torno da questão das doenças sexualmente transmissiveis. $O$ isolamento dos domicílios em relação aos envolvimentos sexuais externos era tido como decisivo para romper as rotas de transmissão entre os que se encontravam, física e moralmente, doentes e os que estavam bem e saudáveis.

A meta da educação nesse campo era, portanto, "...desenvolver uma raça melhor e mais nobre de homens, que sejam senhores de suas paixões em vez de servos delas, como acontece hoje em muitos casos". ${ }^{75}$ Esse regime de contenção sexual interligava-se aos padrões gerais da saúde pública que ressaltavam a autodisciplina e a integridade em todos os planos. Um exemplo disso é extraído de uma discussão realizada em turmas de "pequenas mãos", destinadas a preparar colegiais para tomar conta dos irmãos mais jovens:

"Essas lições precoces prepararão as moças para a cidadania, farão delas pessoas amantes da lei e da ordem, da saúde e da limpeza, da honestidade e da moralidade, garantindo assim uma vizinhança contente e feliz." 76

\section{A educação e os limites do Estado}

As estratégias de reforço de fronteiras definiam as comunidades de modo específico. Quase da mesma maneira, as estratégias educacionais definiam

74. Análises históricas críticas a respeito do desenvolvimento da regulaçāo sexual nesse período encontram-se em Cassell [CASSEL J., The Secret Plague: Veneral Disease in Canada 1838-1929. Toronto, University of Toronto Press, 1987], sobre o Canadá; Brandt [BRANDT A., No Magic Bullet. Nova York, Oxford University Press (ediçāo revista), 1987] sobre os Estados Unidos e Mort [MORT F., Dangerous Sexualities: Medico-MoralPolitics in England since 1830. Londres, Routledge and Keagan Paul, 1987] sobre a Grā-Bretanha.

75. HASTING C., "The Consequences of Prostitution and Suggested Remedies", in Social Service Congress, Report of Addresses and Proceedings, Toronto, Social Service Council of Canada, 1914, p. 213

76. STRUTHERS L.R., The School Nurse. Nova York, G.P. Putnam's Sons, 1917, p. 124. 
padrões de comportamento. A aceitação generalizada desses padrões dependia principalmente do autocontrole, isto é, da adoção voluntária de padrões legitimados como indutores da saúde. Contudo, esses padrões ultrapassavam de muito as questões da transmissão de doenças, assumindo o caráter de códigos gerais de conduta centrados em princípios como a disciplina, a moralidade e a limpeza.

Não há uma linha de separação nítida entre as estratégias de reforço de fronteiras e as estratégias educacionais na área da saúde pública. De fato, uma das maneiras mais importantes de proteger os sadios em relação aos infectados era promover mudanças de comportamento através da educação. Esta era considerada a forma mais importante de atividade sanitária no começo do século. O Secretário de Estado da Saúde de Toronto declarou isso, com toda clareza, em seus discurso de posse na presidência da Associaçāo Americana de saúde pública: “...provavelmente $90 \%$ da eficiência da Administração de saúde pública depende da eficácia de nossas campanhas educacionais". ${ }^{77}$

O lema da Junta Provincial de Saúde de Ontário nesse período era: "Não deixem as pessoas morrer por falta de conhecimento."78 Via-se na ignorância a condiçāo básica de abertura das rotas de transmissão da doença. A meta era usar o conhecimento para bloquear essas rotas.

\section{Influências controláveis}

A ênfase na ignorância, em saúde pública, pode ser encontrada em razōes muito práticas. Chadwick ${ }^{79}$ descreveu o objetivo de seu relatório de 1842 como a identificaçāo das "...circunstâncias removíveis que afetam a saúde das classes mais pobres da população". Esse conceito de "circunstâncias removiveis", ou "influências controláveis", manteve sua influência na prática da saúde pública (por exemplo, John Simon, citado por Frazer; ${ }^{80}$ Newsholme ${ }^{81}$ ). As "circunstâncias removíveis" estavam dentro da capacidade do aparelho de Estado (por exemplo, taxação da riqueza, parâmetros políticos de ação aceitável), funcionando dentro de um esquema que considerava como dadas as relaçōes sociais básicas (trabalho assalariado,

\footnotetext{
77. HASTING G., "Democracy and Public Health Administration". Public Health Journal 10(3), 1919, p. 111.

78. ONTARIO, op. cit, 1920, p. 38.

79. CHADWICK E., Report on the Sanitary Condition of the Labouring Population of Great Britain, op. cit., 1965 , p. p. 75 .

80. FRAZER W.M., op. cit., 1950, p. 90.

81. NEWSHOLME A., The Ministry of Health. Londres, Putnam, 1925, p. 1.
} 
sistema familiar, Estado-nação). Esses limites não eram estáticos, mas modificavam-se de acordo com mudanças nas condições econômicas e políticas e as prioridades da política social.

As influências controláveis, eixo principal das intervenções, variaram através da história da saúde pública. Nos períodos iniciais eram a falta de esgotos e de suprimento adequado de água nas zonas de moradia da classe operária, que Chadwick denominava de "barreiras físicas ao melhoramento". No século XIX, agentes da saúde pública tinham como meta prover a atmosfera doentia dos bairros de classe operária com ar fresco, água limpa e um melhor sistema de esgotos e de despejo de lixo. Na virada do século, o ponto de convergência da saúde pública se deslocou das condições do ambiente físico nos bairros de classe operária para o modo de vida das pessoas nesses locais. A questão central passou a ser o conhecimento e a competência das pessoas da classe trabalhadora (principalmente as mulheres, como dissemos acima) para manter a vida e a saúde de si mesmas e das suas famílias. Como afirmou o secretário de Saúde de Toronto: "Houve uma inclinação do pêndulo a partir do meio ambiente para o indivíduo, do objetivo para o subjetivo". ${ }^{82}$

Em grande parte, o alvo dos aspectos "subjetivos" era a questão da ignorância. Assim como a engenharia sanitária dera mais ênfase à água e à circulação do ar do que aos problemas da pobreza absoluta, as novas teorias da higiene ressaltavam no começo do século mais a ignorância do que a falta de tempo, de recursos ou de comodidades necessárias. Havia maior incidência de doenças entre pessoas da classe operária, não por causa da pobreza e das condições estarrecedoras em que viviam, mas porque elas eram ignorantes. Hastings ${ }^{83}$ afirmou: "São inúmeros os fatores que contribuem para a grande taxa de mortalidade de nossos bairros pobres, entre estes a ignorância talvez seja a mais poderosa."

\section{Ignorância e padrões}

Nos primeiros anos deste século, a saúde pública tinha como alvos a tuberculose, a mortalidade infantil e as doenças sexualmente transmissíveis. Acreditava-se que a ignorância estava subjacente ao predomínio de todas essas condições de doença e constituía a principal "causa removível" em torno da qual deveriam orientar-se as atividades da saúde pública.

82. HASTINGS C., "The Value of the Public Health Nurse in Public Health and Welfare Administration" American Journal of Public Health 9(8), 1921, p. 713.

83. HASTINGS C., "The Modern Conception of Public Health Administration". Conservation of Life 3 $(3 / 4), 1917$, p. 88. 
Havia uma aceitação geral de que a tuberculose e a pobreza estavam relacionadas; no entanto, os funcionários da saúde pública tomavam-na como resultante da ignorância. Um dos principais administradores da saúde pública inglesa escreveu que:

"A tuberculose tem sido descrita como uma doença da miséria... Mas a tuberculose é muito mais uma doença da ignorância, e muitas medidas voltadas para seu tratamento e assistência... têm entre suas conseqüências mais valiosos o treinamento higiennico das pessoas". ${ }^{84}$

Autores canadenses que escreveram sobre a tuberculose compartilhavam essa ênfase na ignorância e na educação. ${ }^{85} \mathrm{Da}$ mesma maneira, o relatório anual da Junta Provincial de Saúde de Ontário ${ }^{86}$ observava que "todas as autoridades consideram que a ignorância desempenha um importante papel no problema da mortalidade infantil..." Quanto às doenças sexualmente transmissíveis, a educação era vista como aspecto central na atividade preventiva da saúde pública, "reconhecendo-se na ignorância geral, na falsa modéstia ou nos padrōes errados de comportamento das diferentes classes um fator de grande relevância". ${ }^{87}$

A última citação ilustra uma importante contradição na educação sanitária da população. O problema não era só a ignorância, mas "os padrões errados". A educação sanitária não preenche um vazio, mas desloca um "saber leigo" preexistente que confere sentido a determinados problemas de saúde e doença ${ }^{88}$ Corrigan $^{89}$ escreveu que se deveria compreender a intervenção do Estado como um deslocamento das organizações existentes e uma repressão das alternativas a elas, em vez de um preenchimento de espaços vazios.

O saber prévio freqüentemente se estrutura de maneira tal que nāo pode ser facilmente deslocado. Ele pode articular-se de modo coerente com outras opiniões, por exemplo a respeito da homossexualidade ou da divisão sexual do trabalho, o que implica a freqüente resistência à educação sanitária. Suas formas mais dramáticas verificaram-se quando certos pro-

84. REINO UNIDO, 1909, pp. 233-4, sublinhado pelo autor.

85. BRYCE P. H., "Tuberculosis: A Disease of Insanitary Living". Conservation of Life 4(1), 1918, pp. $15-6$.

86. ONTARIO, op. cit., 1918, p. 25.

87. HAMILTON L.A., "The Subcommitee on Women's Activities". Public Health Journal 9(2), 1918, p. 58.

88. WARWICK I., AGGLETON P. e HOMANS H., "Young People's Health Beliefs and AIDS", in P. Aggleton e H. Homans (eds.), Social Aspects of AIDS, Londres, The Falmer Press, 1988.

89. CORRIGAN P., State Formation and Moral Regulation in Nineteenth Century Britain: Sociological Investigations. Tese de Doutorado. Durham University, 1977, pp. i-iii. 
gramas, como a vacinação obrigatória, encontraram oposição de massa, não obstante todos os esforços educacionais (veja-se Bator ${ }^{90}$ e Porter e Porter ${ }^{91}$ ).

Contudo, na realidade, a educação sanitária tem funcionado como se estivesse preenchendo um vazio de ignorância em vez de lidar com outra forma de conhecimento. Além disso, a educação sanitária deveria fazer mais do que apenas apresentar um saber científico sobre como evitar doenças; ela deveria promover e desenvolver padrões de comportamento. Conceitos como os de disciplina e de ordem eram recorrentes no discurso da saúde pública do começo deste século. A teoria da ignorância marcou a área da saúde pública como provedora dos padrões estatais de combate à ignorância, à superstição e ao comodismo. Essas idéias foram resumidas pelo secretário de Saúde de Toronto em seu discurso como presidente da Associação Americana de saúde pública:

"A atual Administração de saúde pública exige que as pessoas se conformem a determinadas regulamentações. Nós procuramos ensiná-las a viver. "92

A educação pela saúde pública fornecia uma maneira valiosa e palatável de "ensinar as pessoas a viver". Nas palavras de um funcionário canadense:

"O temor da doença e o medo de suas conseqüências cruéis e fatais constituem um freio mais poderoso contra o vício do que toda a advertência moral, destituída do apoio da ciência." 93

\section{Continuidade: a AIDS e a saúde pública}

A era da nova higiene, no início do século $\mathrm{XX}$, marcou um ponto alto no desenvolvimento da saúde pública como forma de política social. Depois de 1920, os parâmetros da saúde pública começaram a estreitar-se. ${ }^{94} \mathrm{De}$ grande instrumento da reforma social, ela se tornou uma especialidade

90. BATOR P., "The Health Reformers versus the Common Canadian: The Controversy Over Compulsory Vaccination Against Samllpox In Toronto and Ontario 1900-20". Ontario History, 75(4), 1983.

91. PORTER D. e PORTER R., "The Enforcement of Health: The British Debate", in E. Fee e D. Fox (eds.) AIDS, 1988.

92. HASTINGS C., "Democracy and Public Health Administration". Public Health Journal 10(3), 1919, p. 99, ênfase do autor.

93. SMYTHE A.E.S., "The Subcommittee on Education". Public Health Journal 9(3), 1918, p. 72.

94. LEWIS J., What Price Community Medicine? Brighton, Wheatsheaf, 1986, pp. 2-6. 
menor dentro da teoria e da prática médicas. ${ }^{95}$ Em linhas gerais, a expansão das disponibilidades de tratamento e de financiamento tornou-se prioridade em relação à prevenção da doença através da promoção de mudanças no meio ambiente e no comportamento. ${ }^{96}$

Ao longo da década de 1970, a atenção dos formuladores de política e dos críticos voltou-se outra vez para a saúde pública, por duas razões. A crítica radical da medicina, que se desenvolveu nesse período, viu na saúde pública uma alternativa positiva à medicina convencional, desafiando o monopólio dos médicos, o predomínio das preocupações comerciais e a concentração nos indivíduos em vez das condições sociais (por exemplo, Turshen ${ }^{97}$ ). Ao mesmo tempo, formuladores governamentais de políticas revelavam grande preocupação com os custos da provisão dos serviços de atenção médica, cada vez mais caros, num momento em que a prosperidade do após-guerra entrava em declínio. A saúde pública mostrou-se atraente para os formuladores de políticas como método de redução de custos através de intervenções sociais para evitar a doença e diminuir a utilização de tratamentos hospitalares muito dispendiosos..$^{98} \mathrm{O}$ resultado foi a elaboração de documentos de grande influência, como o relatório Lalonde, que acentuava a promoção da saúde voltada para a mudança de escolha de estilos de vida. Uma espantosa quantidade de moléstias foi atribuída a "riscos auto-infligidos", tais como o uso do álcool e de drogas, alimentação deficiente, falta de exercícios, maus hábitos dos motoristas, e a "promiscuidade e negligência que causam a sífilis e a gonorréia". ${ }^{99} \mathrm{Com}$ isso, manteve-se a ênfase no "ensiná-los a viver" da nova higiene, embora com algumas modificações.

95. Essa mudança foi marcada por acontecimentos como a exclusāo de membros leigos da Associação Canadense de saúde pública, o conteúdo crescentemente técnico das revistas, a tendência para definir o tratamento anterior da doença como preventation e os resultados limitados do novo departamento de saúde, de nível ministerial, entre 1920 e 1945 (Bator [BATOR P., Saving Lives on the Wholesale Plan: Public Health Reform in the City of Toronto, 1900-30. Tese de Doutorado, Universidade de Toronto, 1979a, pp. 346-8]: McGinn is, [McGINNIS J.P.D., From Health to Welfare: Federal Government Policies Reagarding Standards of Public Health for Canadians, 1919-45. Tese de Doutorado, University of Alberta, 1980, p. 39].

96. Foge ao escopo deste artigo discutir as razōes desse declínio. Lewis [LEWIS J., What Price Community Medicine? Brighton, Wheatsheaf, 1986, pp. 3,11] explica o declín io em termos de uma falha filosófica dentro da saúde pública, um fracasso na construçāo de uma abordagem ampla da saúde comunitária. Gostaria de ir mais adiante, ressaltando o lugar da saúde pública entre as mudanças nas prioridades da política social.

97. TURSHEN M., "The Political Ecology of Disease". The Review of Radical Political Economics (9)1, 1977.

98. FARLOW D.M., "Achieving Health for All”. Health Sharing 8(3), 1987.

99. LALONDE M., A new Perspective on The Health of Canadians. Otawa, Government of Canada, 1974, pp. 17-32. 
A principal modificação era que a ênfase anterior na transformação da vida familiar através da regulação era suplantada pela convocação à população como consumidores atomizados. Em vez de tentar reformar as relações familiares através da intervenção direta (que, nos anos 70, era terreno exclusivo do serviço social), a nova saúde pública podia ser considerada um esforço para mudar as escolhas dos consumidores por meio de vistosas campanhas publicitárias (por exemplo, contra o fumo, a favor da prática de exercícios e contra dirigir alcoolizado).

Era essa a situação da saúde pública quando ela teve de encarar seu maior desafio na segunda metade do século, a crise da AIDS. Houve uma signifiçativa continuidade com a ênfase anterior no reforço de fronteiras e na educação, encontrado na nova higiene, embora modificada pela emergência do tema dos estilos de vida dos anos 70 .

O reforço dos vínculos comunitários através de medidas excludentes tem sido um tema principal das reações à AIDS e à infecção pelo HIV. Em geral, a direita política e religiosa, mais do que os funcionários da saúde pública, têm defendidò a adoçāo de formas extremas de repressão, como a obrigatoriedade dos testes de HIV e o isolamento ou a quarentena. ${ }^{100}$ Do ponto de vista da saúde pública, essas medidas são totalmente ineficazes, exigem gastos muito elevados e parecem ser contraproducentes na prevenção da transmissão da doença, pois impelem as pessoas a fugir do tratamento ou do aconselhamento (veja-se em MacKinnon e outros; ${ }^{101}$ Frazer e outros; ${ }^{102}$ Connor ${ }^{103}$ ). Isso não evitou que o governo dos Estados Unidos, entre outros, introduzisse programas compulsórios de controle do HIV entre imigrantes e viajantes, com a exclusão dos que se revelam soropositivos.

Os agentes da saúde pública têm manifestado uma oposiçāo unânime à prisão indiscriminada de pessoas infectadas pelo HIV. Muitos outros, porém, têm dado apoio à idéia da detenção das pessoas portadoras de anticorpos de HIV que "intencional" e "irresponsavelmente" transmitem o vírus através da atividade sexual ou doação de sangue (Connor; ${ }^{104}$

100. BAYER R., "AIDS, Power and Reason". The Milbank Quarterly 64 (suplemento II), 1986, pp. 175-7. 101. MACKINNON M., CATTRELLE K., KREVER H., "Legal and Social Aspects of AIDS in Canada", in Royal Society of Canada, AIDS: Perspectives for Canadians: Background Papers. Otawa, Royal Society of canada, 1988, p. 9.

102. FRASER R., COATES R., DUCKETT M., FANNING M., REMIS R., "Public Health Imperatives of HIV Infection and AIDS in Canada" in Royal Society of Canada. AIDS: Perspectives for Canadians: Background Papers. Otawa, Royal Society of Canada, 1988, p. 140.

103. CONNOR S., "AIDS: Social, Legal and Ethical Issues of the "Third Epidemic" in Pan-American Health Organization, AIDS: Profile of an Epidemic. Washington, Pan-American Health Organization, 1989 , pp. 14, 157. 
Allen ${ }^{105}$ ). Embora a prisão seja possível segundo a legislação da saúde pública, no Canadá tem se recorrido mais à denúncia criminal. Esse método, porém, ainda é altamente problemático, pois estimula a irresponsabilidade, tanto pela falsa promessa de que o Estado vai cuidar das pessoas possíveis transmissoras da doença, desencorajando a prática dos testes, quanto por trazer medo e confusão para as pessoas que se envolvem em atividades de alto risco, além de legitimar o impulso punitivo que continua a ligar AIDS e culpa (Gostin; ${ }^{106}$ Bayer; ${ }^{107}$ Sullivan e Field ${ }^{108}$ ).

Mais importante do que o isolamento de fato é o impacto da ideologia da repressão que tem sido usada para estabelecer fronteiras entre populações infectadas e não infectadas. Desde o começo, a saúde pública identificou a AIDS como um problema de "grupos de risco" estigmatizados, em oposição à "população em geral" (Grover; ${ }^{109}$ Kuller e Kingsley;110 Adam $^{111}$ ). De fato, os agentes da saúde pública imaginam uma espécie de fosso entre essas populações, ameaçadas por certas "pontes de transmissão". Walters ${ }^{112}$ afirmou que "os usuários de seringas representam a ponte mais ampla através da qual se dissemina o HIV na população em geral”.

A conseqüência imediata desse sentimento restrito de comunidade tem sido o que alguns denominam de "terceira epidemia", de "jogar a culpa nos outros" (Sabatier; ${ }^{113}$ Johnston ${ }^{114}$ ). Não só os gays e os usuários de drogas são acusados de fazer mal a si mesmos e à sociedade, mas também os cubanos culpam os estrangeiros, os russos os americanos, os americanos os africanos ou haitianos, os pequenos centros jogam a culpa nos grandes centros, num padrão que se repete interminavelmente (Nelkin e

104. CONNOR S., op. cit., pp. 155-7.

105. ALLEN G., "AIDS and Civil Rights". MacLean's 101 (41), 1988, p. 50. Em 1989, três casos canadenses famosos em Halifax, Otawa e Calgary, levaram a penas de reclusão pela transmissão de infecção pelo HIV. Cada um desses casos recebeu extensa publicidade (por exemplo, no Toronto Star de 15 de agosto de 1989 e no editorial do Globe and Mail de 18 de agosto do mesmo ano).

106. GOSTIN L., "Traditional Public Health Strategies", in H. Dalton et al. (eds.), AIDS and the Law. New Haven, Yale University Press, 1987, p. 61.

107. BAYER R., "AIDS, Power and Reason”, The Milbank Quarterly 64 (suplemento II), 1986, pp. 177-8.

108. SULLIVAN K.M. e FIELD M.A., "AIDS and the Coercive Power of the State", Harvard Civil Rights and Civil Liberties Review 23(1), 1988, p. 197.

109. GROVER J., "Keywords", in D. Crimp (ed.), AIDS; Cultural Analysis, CulturalActivism. Cambridge, MIT Press, 1988, p. 27.

110. KULLER L. e KINSLEY L., "The Epidemic of AIDS; A Failure of Public Health Policy". The Milbank Quarterly 64 (suplemento I), 1986, p. 64.

111. ADAM B., "The State, Public Policy and AIDS Discourse". Contemporary Crises 13, 1989, pp. 3-9.

112. WALTERS D., "Needle Exchanges Needed Now". The New Facts of Life 2(2), 1988, p. 3.

113. SABATIER R., Blaming Others; Prejudice, Race and Worldwide AIDS, Londres, Panos, 1988.

114. JOHNSTON R.C., "AIDS and Otherness", in J. Griggs (ed.), AIDS: Public Policy Dimensions, Nova York, United Hospital Fund of New York, 1987. 
Gilman;115 veja também Molinert e outros $\left.{ }^{116}\right)^{117}$. Isso não é apenas uma aberração decorrente da emergência da AIDS em grupos anteriormente oprimidos, mas deriva da construção social da comunidade como um agrupamento restrito, que emana do Estado e gira ao seu redor.

Além dos programas de reforço de fronteiras, a educação tem sido uma prioridade no trabalho da saúde pública em torno da AIDS. Um relatório do governo da província de Alberta ${ }^{118}$ afirmou: "O único método disponível de controle da difusão da AIDS em Alberta é um programa abrangente de educação pública baseada na comunidade." Com efeito, o slogan inglês “AIDS: Não Morra por Ignorância” poderia ter sido retirado dos arquivos dos serviços de saúde pública. ${ }^{119}$

Em concordância com a ênfase nos estilos de vida, que se desenvolveu durante os anos 70, têm sido lançadas algumas campanhas vistosas, destinadas a alterar as escolhas (em geral, através da televisão e transmitidas bem tarde da noite). Como é típico no tema dos estilos de vida, algumas dessas campanhas têm um forte tom de vitimização e culpa, que se vincula à premissa de que a doença é auto-infligida em virtude de más escolhas. Mais importante ainda é que essas campanhas não conseguem se ligar ao saber leigo, bastante complexo, que cerca a infecção pelo HIV, além de cruzarem e que cruzam com uma série de opiniões acerca dos gays, das lésbicas, dos usuários de drogas, dos imigrantes, do comportamento sexual correto e do contágio (Watney; ${ }^{120}$ Bayer $^{121}$ ). O saber leigo combinado com as abordagens dos estilos de vida tende a refletir-se na persistência das declarações de que a AIDS é de alguma maneira “auto-infligida”, que o

115. NELKIN D. e GILMAN S., "Placing Blame for Devastating Disease". Social Research 55(3), 1988.

116. MOLINERT H. et al., "Prevalence of Infection with Human Immunodeficiency Virus in Cuba", in Pan-American Health Organizations, AIDS: Profile of an Epidemic. Washington, Pan-American Health Organization, 1989 , p. 94.

117. É claro que a responsabilidade pela "terceira epidemia" nāo cabe totalmente aos agentes da saúde pública. Com efeito, muitos deles superaram o uso de uma linguagem explicitamente excludente (Toronto, 1984). Eles continuam, porém, a fundar suas atividades em concepçōes implícitas excludentes da comunidade e de seus membros.

118. ALBERTA. Comunity and Occupational Health. Education and Caring: Alberta's Program for the Prevention, Management and Control of AIDS, 1987, p. 1.

119. Veja a crítica deste slogan em Watney [WATNEY S., "The Spectacle of AIDS", in D. Crimo (ed.) AIDS: Cultural Analysis, Cultural Activism. Cambridge, MIT Press, 1988, pp. 72-2] Veja também o Ontario Ministry of Health Aids Awareness Week Ad, que afirma: "Alguns dizem que a ignorância é uma bem-aventurança. Quando se trata de sexo, a ignorância está longe de ser uma bem-aventurança. Ela é um evidente perigo."

120. WATNEY S., "The Spectacle of AIDS", in D. Crimo (ed.)AIDS: Cultural Analysis, CulturalActivism. Cambridge, MIT Press, 1988, p. 77.

121. BAYER R., "AIDS and the Gay community: Between the Specter and the Promise of Medicine". Social Research, 52(3), 1985, pp. 586-7. 
assim chamado "vírus da AIDS" pode ser casualmente transmitido e que as pessoas que adotam um comportamento conforme à moral estão imunes à infecção (exceto naquelas lamentáveis ocasiões em que são "vítimas inocentes").

Combater esse saber leigo exige mais do que pronunciamentos técnicos a respeito da natureza da infecção pelo HIV. Ao invés, implica a refutação do complexo de crenças que liga a saúde a padrões determinados de moralidade e que colocam no mesmo saco a doença, o desvio, a imoralidade e a diferença (veja-se Homans e Aggleton ${ }^{122}$ ). Porém, a saúde pública tem muitas vezes reforçado, em vez de contestar, essas crenças. ${ }^{123}$

As crenças são freqüentemente reforçadas quando as medidas de saúde pública promovem e impõem determinados padrões morais. Por exemplo, discussões cheias de juízos de valor a respeito da "promiscuidade" podem ser encontradas em grande parte das respostas da saúde pública à AIDS. ${ }^{124}$ Last declarou em um editorial do Canadian Journal of Public Health ${ }^{125}$ que "os homossexuais, como aliás todo mundo, deveriam ser dissuadidos do estilo de vida promíscuo que parece fazer parte dos hábitos de tantos deles".

Esse tipo de linguagem sugere mais um julgamento moral do que uma advertência acerca da transmissão da doença. Há uma quantidade enorme de exemplos em que a informação útil a respeito do sexo seguro e do uso seguro de drogas foi suprimida em troca de mensagens inúteis e pretensiosas acerca da monogamia e da abstenção das drogas. Se a educação é a primeira prioridade no combate à AIDS, ela ainda tem um longo caminho pela frente. É claro que até mesmo a campanha mais competente seria inadequada se não se voltasse para os obstáculos sistemáticos à mudança do comportamento, especialmente os problemas de acesso a recursos (preservativos, seringas etc.) e à capacidade de tomar decisões (por exemplo, o impacto da opressão das mulheres sobre sua capacidade de exigir o uso de preservativo nas relações sexuais).

122. HOMANS H. e AGGLETON P., "Health Education, HIV Infection and AIDS", in P.Aggleton e H. Homans (eds.), Social Aspects of AIDS. Londres, The Falmer Press, 1988, pp. 160-2.

123. WATNEY S., "The Spectacle of AIDS", in D. Crimo (ed.)AIDS: CulturalAnalysis, CulturalActivism. Cambridge, MIT Press, 1988, p. 80.

124. OPPENHEIMER G., "In the Eye of the Storm: The Epidemiological Construction of AIDS", in E. Fee e D. Fox (eds.), AIDS, 1988, p. 278.

125. LAST J.M., "Ethics, Mores and Values — and AIDS". CanadianJournal of Public Health 78(2), 1987, p. 75. 


\section{Conclusões: a saúde pública, o Estado e a teoria social}

Este artigo pretende ser uma contribuiçāo a um projeto inacabado de explicação da política social pela teoria marxista do Estado. O projeto, iniciado na década de 70 , foi em grande parte abandonado durante as mudanças teóricas dos anos 80 . Posso defini-lo como inacabado porque havia necessidade de ampliar o debate teórico e aprofundar o trabalho empírico para elaborar melhor os estudos iniciais, que continham insuficiências.

As análises mais perspicazes a respeito da AIDS e das políticas de saúde pública até aqui feitas tendem a rejeitar esse projeto, de modo implícito ou explícito, em troca de uma "análise cultural". Isso representa uma perda significativa. Tal opção sacrifica a vertente crítica da compreensão da saúde pública como política social, refletindo a natureza e as limitaçōes específicas do Estado capitalista. Mais importante ainda é que essa escolha representa um distanciamento da estratégia política baseada numa concepção do Estado como ponto de concentração do poder na sociedade capitalista. O resultado tem sido a produção de insights valiosos mas desconexos (com exceção de algumas afirmações voluntaristas) de uma estratégia mais ampla de transformação social.

\section{RESUMO}

\section{Ensiná-los a viver: a política de saúde pública da tuberculose a Aids}

A crise da AIDS tem despertado grande interesse na exame crítico da política de saúde pública. Boa parte dessa reflexão tem seguido a perspectiva da "análise cultural" em que se combinam as teorias pós-modernas com a perspectiva política do "pluralismo radical". Essa combinação constitui uma rejeição da teoria marxista do Estado e, além disso, desvia a atenção do Estado como objeto de análise. Este artigo apresenta-se como uma resposta à "análise cultural", utilizando uma investigação histórica sobre a política de saúde pública no Canadá para mostrar como esta tem se concentrado no Estado e para refletir sobre a natureza e os limites da política social. 


\section{ABSTRACT \\ 'To Teach Them How to live'. The Politics of Public Health from Tuberculosis to AIDS}

The AIDS crisis has aroused considerable interest in the critical examination of public health. Much of this work has come from the perspective of cultural analysis combining postmodernist theories with the politics of 'radical pluralism'. This work constitutes a rejection of Marxist state theory, and indeed has directed attention away from the state as an object of inquiry. This article is a response to 'cultural analysis', which uses an historical examination of public health in Canada to show the ways in which it has been oriented around the state, reflecting the character and limites of social policy.

\section{RESUME}

En les enseignant à vivre: la politique de santé publique de la tuberculose jusqu'au SIDA

Le SIDA a attiré l'attention vers l'examen critique de la politique de santé publique. La plupart de ces études ont suivi la perspective de "l'analyse culturelle" où les théories post-modernes se combinent avec la perspective politique du "pluralisme radical". Cette combinaison constitue un rejet de la théorie marxiste de l'État et méprise l'importance de l'État comme objet d'analyse.

Cet article se presente comme une réponse à "l'analyse culturelle" en utilisant une recherche historique sur la politique canadienne de santé publique nettement axé sur l'État. 